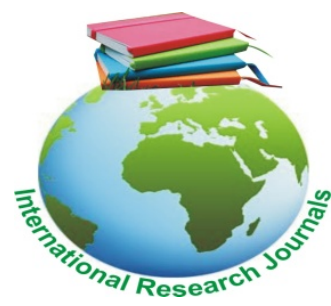

Educational Research (ISSN: 2141-5161) Vol. 7(3) pp. 088-094, May, 2016

Available online@ http://www.interesjournals.org/ER

DOI: http:/dx.doi.org/10.14303/er.2016.134

Copyright (c) 2016 International Research Journals

Full Length Research Paper

\title{
Impacts of low enrolment in Secondary Schools physics to attainment of Kenyan Vision 2030: A case study of Nandi North Sub County
}

\author{
Murei Gilbert Kiptum \\ Department of Physics, Laikipia University, P.O. Box 1100-20300, Nyahururu Kenya \\ Corresponding Author's Email: gilbertmurei@yahoo.com
}

\begin{abstract}
The objectives of Kenyan secondary school physics curriculum is to build a firm foundation for further education and training as well as technological and industrial development. Physics curriculum emphasizes the experimental approach which should prepare the learner to teaching and learning scientific concepts and ideas in the modern technology. Hence by the end of the course, the learners should be able to use scientific knowledge to enhance development of industries and propel country to achieve vision 2030. Despite the importance of physics, the performance and enrolment of students in Physics has not been impressive. The study seeks to establish factors that contribute to low enrolment of physics in Kenyan secondary schools. This study will specifically looked into students' attitudes towards physics subject, the difficult that physics teachers have in handling physics topics and the relationship between KCPE performance in science and physics performance. The study adopted descriptive survey design. The study was conducted in Nandi North sub County and the target population was teachers and students in 35 secondary schools in the area of study. The study employed the use of stratified and simple random sampling to select the respondents. Questionnaire and document analysis was used in data collection. It was established that students have a formed opinion on the nature of the subject, majorly on difficulty level and having mathematical manipulations which scares them off. Teachers find most of the topics in physics easy to handle, however, some topics like electromagnetic induction, Electronics and Waves tend to be challenging. Document analysis of KCPE results revealed that learner's background in primary science was weak. There are far fewer high school students enrolled in physics and realizing the required grades, thus the Kenyan vision 2030 remains just a mirage. It was recommended among others that teachers teaching Physics and Mathematics should work in consultation with each other so as to help the students in appreciating the role of Mathematics in Physics.The findings have implications for designing interventions and identifying pedagogical techniques that link primary science and secondary school physics.
\end{abstract}

Keywords: Enrolment, physics, Secondary school, science, Vision 2030.

\section{INTRODUCTION}

Before the beginning of the nineteenth century, the study of science was either a hobby of the few people with means or solitary effort of someone with scientific talent. Since then science has developed to a level where we today live in scientific civilization in which science is no longer confined to a few individuals or countries that are devoted (Momanyi, 2010). However, less than half of the world's population ventures in science education.
Science is involved in food production, preservation, health care, transport systems, telecommunication and energy conservation. Science affects all aspects of human life. Every person in society requires scientific knowledge in order to fit in the present society. Thus the teaching of science has become part of the general education of the society.

Physics, the branch of science concerned with the 
nature, structure and properties of matter contributes enormously to the economy of any country. It plays a central role in many different sectors of industry such as telecommunications, architecture, engineering, electricity production and transmission, construction, and transport. It also provides employment for people who are in occupations that are engaged in physics as a scientific discipline for example teachers, scholars, and other researchers. It is thus an indispensable part of any country's economic development. Furthermore, physics often provides the foundations for other disciplines such as biology, medicine and chemistry. It enables learners to develop analytical skills necessary for problem solving in various situations they encounter in life (Adeoye, 2010).

Physics is believed to be one of the oldest and probably the most developed of all the sciences (Keith1996). It addresses the most fundamental questions regarding the nature of the physical universe. It asks questions such as; what is the nature of the universe? What is matter made of? What are the fundamental forces of nature? Because physics is the study of these and other basic questions, it provides the underpinnings for all other physical sciences. 'The ultimate description of all physical systems is based on the laws of physical universe usually referred to as the laws of physics (Nathan et al 1995). Two dominant themes run through the development of physics; matter and energy, the search for order and patterns. Secondary school physics is primarily concerned with the study of these two very important themes.

The decline in enrolment and graduation rate in physics in all levels has been the case in many countries including the USA, UK and Netherlands (Osborne et al 2003). In a study carried out by (Lyons 2005) in Australia, many students regarded junior high school science as irrelevant, uninteresting and difficult leaving them with few intrinsic reasons for enrolling in senior school physics courses. The decline in enrolment in science subject in general and physics in particular, is promoting question about the future level of scientific literacy and technological expertise (UNESCO 1973).

Some of the objectives of secondary education in Kenya under the 8-4-4 curriculum include;- building a firm foundation for further education and training and building foundation for technological and industrial development. In the same line, the physics syllabus presents physics as a body of knowledge about the physical environment (K.I.C.D, 2002). It emphasizes the experimental approach which should prepare the learner to teaching and learning scientific concepts and ideas in the modern technology. Hence by the end of the course, the learner should be able to contribute to the technological and industrial development of the nation (K.I.C.D, 2002).

Kenya has implemented a number of curriculum reforms in science education such as Nuffield Science Project (1966), UNESCO Science Project (1969), School Science Project (1974) and now 8-4-4 curriculums. In all these curricular, Physics has been one of the corner stones for national development. In industries, physics also makes significant contributions through advances in new technologies that arise from theoretical break through. For example, advances in the understanding of electromagnetism and nuclear physics led directly to the development of new products which dramatically transformed modern-day society devices, such as television, computer, domestic appliances and nuclear weapons. In addition; advances in thermodynamics led to the development of industrialization while advances in mechanics; inspired the development of calculus (Wikipedia encyclopedia, 2000).

Physics prepares students for vocations and careers at tertiary levels of learning and it is like a pivot joint in the Kenyan Secondary Schools Curriculum; since other subjects such as Chemistry, Biology and Geography depend on it (Otieno, 2009). It develops the scientific habits in students, which are transferrable to other areas in life. Such habits involve non-reliance on superstition, critical thinking and respect for other people's opinions which when embraced can solve many problems of individual and social living. Physics helps the learners to develop critical thinking due to its high reliance on mathematical concepts and logics. Boyes and Dickson (2003) noted that the fact mathematics is not a favorite subject for most low performing students could be a reason why they shy away from physics. Students who perform well in mathematics are likely to enroll and perform better in physics; this could be the reason why the students who enroll in physics have an overall better performance. Despite the fact that physics has made a significant contribution to life in today's society, a decline in enrolment and performance has been registered over the years (KNEC 2002 to 2011).

In Kenya, physics education will play a catalyzing role in the realization of Vision 2030, the country's national plan to become an industrialized nation by the year 2030 (MOEST 2007). . It is therefore important for Kenyan students to be well grounded in physics education to guarantee Kenya's economic development. In recognition of this, the Kenyan government in 1984 made physics a compulsory subject for all learners in the first two years of secondary education. This move was aimed at ensuring that learners have a basis for understanding the applications of physics in real life situations.

Despite the importance of physics, evidence shows that enrolment and performance in the subject has been poor (K.C.S.E results, 2014). Most of the courses at university level in Kenya require that a student should have done physics in the K.C.S.E examination. In fact, physics is so important that for some degrees and diploma courses, it is taken in place of mathematics where the student has not performed very well for a course that requires a good pass in mathematics, Joint Admissions Board (JAB, 2011). Although the problem of low enrolment in physics may seem to be small, $80 \%$ of 
science courses at University require physics. Therefore, small numbers of students enrolling in physics threatens to add another impediment to Kenya's efforts in achieving vision 2030 (G.O.K, 2007). Under the 8-4-4 system of education in Kenya, pupils take 8 years in primary schools and sit for the Kenya Certificate of Primary Education (K.C.P.E) examinations. Students who merit join form one and at form two levels; they are allowed to study at least eleven subjects. But at form three, under Kenya Certificate of Secondary Education ( K.C.S.E) curriculum, a student is supposed to select two science subjects which are compulsory out of the three science subjects offered in school namely:- Physics, Chemistry and Biology, Kenya Institute of Curriculum Development (K.I.C.D, 2002). It is observed from the past years that few students take Physics as compared to the number of students who choose Chemistry and Biology (K.N.E.C., 2014).

Enrolment of physics in KCSE is always less than that of other science subjects namely chemistry and biology. This trend is even more significant among schools in rural areas than in urban areas (MOEST 2007). Likewise, students in high performing schools are more likely to enroll and perform better in physics than low performing schools. All schools in the district are in the rural setting and enrollment in physics is significantly low. The most common problem confronted by secondary school physics teachers today, is that physics is perceived to be a difficult subject which deters them from opting to study it beyond junior high school level. As a result, students are missing the opportunity to study many interesting and important concepts that could provide them with an insight into the physical world and the universe in which they exist (AAPT Journal 1997). Of those who are sufficiently motivated to study the subject, many find physical concepts abstract and difficult to grasp. Misconceptions about physical phenomena persist among physics students despite the frequent use of experiments to verify the theories (Lyons 2005). Shift from demonstration to problem solving in order to promote the construction of physics concepts. The review in this chapter focused on factors that were assumed to affect enrolment and performance in physics among secondary school students.

Despite the fact that the physics syllabus has constantly been revised with a view to make it more appealing to the students, performance in the subject has not improved (KNEC 2007). There is a very close relationship between performance and enrolment (Nderitu 2007, Lyons 2005) student's poor performance in a national exam is likely to cause a low enrolment in the preceding classes. Probably this is the reason why there has been a low enrolment in physics. Over the years, there has been low performance in physics though the mean score for chemistry has been slightly lower than physics; there has been a great disparity in enrolment between the two subjects in favour of chemistry (KNEC
2002). It may not be clear whether performance in a subject enrolment but perception of difficulty in a subject is also likely to affect enrolment.

Enrolment in Physics probably also be linked to gender, performance in Physics examinations and school timetabling. Gender refers to the male or female sex (Semela, 2010). Mallory (2004), observed that gender difference in interest seems to be sufficiently explained by gender stereotypic beliefs among boys and girls which have a direct influence on enrolment in Physics. There is a very close relationship between enrolment in Physics subject and its performance. Improvement in Physics performance is likely to attract higher enrolment and for this to happen, teachers and administrators need to provide a conducive environment which includes providing for resources and innovative teachers.

Physics enrolment in Nandi County is still low compared to other two science subjects. In the year 2010 Physics had $29.4 \%$ enrolment, compared to $99 \%$ of Chemistry and Biology. Performance of Physics is also low compared to Biology. It is against this background that the study sought to investigate the low enrolment and poor performance in physics and particularly for girls in secondary school.

\section{METHODOLOGY}

\section{Research design}

The study adopted descriptive survey design. A descriptive survey study seeks to describe a unit in detail in context and holistically (Kombo and Tromp 2006). The design was relevant to this study as it allowed collection of data necessary for establishing low enrolment of physics subject by secondary school students.

\section{Study area}

The study was conducted in Nandi North Sub County. The Sub County is located in Nandi County. It has several secondary schools of different categories. The sub County has no National school, but has four extra County schools, sixteen (16) county schools and fifteen (15) sub county schools.

\section{Target Population}

Nandi North Sub-County has thirty five (35) secondary schools, with an estimated population of over 1600 students. The subjects of the study were drawn from some selected secondary schools in the Sub County. The respondents included heads of science department, physics' teachers and Form Three Physics' students so as to make the study diverse and representative. 
Kiptum, 091

Table 1: Motivation of students to enroll in physics

\begin{tabular}{lcc}
\hline Motivation & Frequency & Percent \\
\hline Physics teacher & 189 & 70 \\
Students & 40 & 14.8 \\
Parents & 20 & 7.4 \\
Self motivation & 4 & 5 \\
\hline
\end{tabular}

Table 2: Teachers opinion on difficulty in handling physics topics

\begin{tabular}{lcc}
\hline Topics & Frequency & Percent \\
\hline I handle all topics easily & 21 & 52.2 \\
Handle topics in physics with difficulty & 5 & 12.5 \\
I handle some topics in physics with some difficulty & 14 & 35.0 \\
\hline
\end{tabular}

Table 3: Comparison of performance of science in KCPE and Physics performance

\begin{tabular}{lcc}
\hline Topics & KCPE performance in Science & End of term physics performance \\
\hline A & $10(3.7 \%)$ & $0(0.0 \%)$ \\
B & $50(18.5 \%)$ & $42(15.5 \%)$ \\
C & $179(66.6 \%)$ & $168(62.2 \%)$ \\
D & $31(11.0 \%)$ & $44(16.2 \%)$ \\
E & $0(0.0 \%)$ & $16(5.8 \%)$ \\
\hline
\end{tabular}

\section{Sampling Procedure and sample size}

Sampling is the process of selecting a number of individuals or objects from a population such that the selected group contains elements representative of the Characteristics found in the entire group (Kombo and Tromp 2006). The study employed the use of stratified and simple random sampling to select the respondents. The schools were stratified into Extra County, County and Sub- County schools. The schools were selected using simple random sampling from each stratum. 30\% of all the schools were randomly selected; hence the sample size for the study was 10 schools which composed of 2 extra County schools, 4 County schools and 4 Sub County schools.

\section{Data collection instruments}

Questionnaires and interviews were used to collect data. The questionnaires were presented to physics teachers while interviews were conducted on the Heads of science department. The study employed a student questionnaire as an instrument to determine the attitude the students have on physics. This was done through stratified sampling of Form Three students in all schools sampled for both low and high performing schools in the study area.

\section{Data analysis}

The data was analyzed using descriptive statistics; frequency and percentages and presented using tables.

\section{RESULTS AND DISCUSSION}

Majority of the students $80 \%$ indicated to have developed negative attitude towards physics subjects particularly due to abstractness and difficult level involved. These resulted from the connotations stereotype attached on it where the subject is believed to be difficult thus lowers the enthusiasm of students to enroll. Furthermore, respondents expressed opinion that, since physics was difficult and challenging subject, there was high chance of obtaining a lower grade.

Creative thinking has been instilled in learners through teachers' initiatives. This is done through encouragement towards engagement of practical activities geared towards physics. $70 \%$ of the students strongly agreed that, the encouragement is received from teachers 
towards the subject, however $14.8 \%$ indicated that it was their own initiative that spirited them in reading the subject, $27.4 \%$ also pointed out that, neither of the parents nor teachers had influence and $1.4 \%$ never made any recommendation. This indicates that, much of the support students get towards physics comes from their teachers. Teachers of physics therefore play crucial role in developing students in the learning of physics. However as opposed to outstanding performance of students in other subjects, the performance of students in physics was low due to the negative attitude towards the subject. The attitude towards a subject has a direct effect on the performance. Positive attitude can be associated with high performance while negative attitude is associated with poor performance in the subject, (Kariuki, 2007).

\section{Teachers' difficult level in teaching physics}

The researcher further used interview schedule and questionnaire to source information from teachers on the difficulty levels in the teaching of the subject and challenging topics to handle. Out of the 30 teachers $52.5 \%$ indicated that most of the topics are easily handled, however, $12.5 \%$ indicated that some topics like electromagnetic induction, reflection, electronics and waves are challenged by students level of understanding and $35 \%$ never commented on the item.

The study established that, teachers find all topics in physics easy to handle despite the negative attitude of students towards it. This could be as a result of high competency in training of teachers as indicated by high qualifications thus affect instruction in physics. Identified topics like electromagnetic induction, reflection and waves are only but some of the difficult to comprehend on the side of learners; however, these are said to be tackled by the most experienced teachers in schools. Furthermore, few teachers still believe that some topics are challenging to present especially mathematical part of it and it's justified by the fact that mathematics appears to be challenging to learners.

Physics students work hard in class, the study established that $79.2 \%$ of learners have shown high interest in studying the subject, and $7.4 \%$ fairly work harder given that they are very weak in mathematical skills. It was found that $13.3 \%$ do not work hard in the subject. The study further established that, the indicated proportions results from motivational part of the subject when one excel in the subject; he or she qualifies for a marketable course like engineering course which has good remunerations (Mwangi, 1983). The handling of difficult topics in physics should be a collective responsibility of the parents, teachers, learners and other education stakeholders.

The difficult topics in physics can be handled through proper lesson delivery, better teaching method or strategy excellent evaluation policies and motivation of the learners, (Waititu, 2004).

\section{Performance in primary school science and physics in high school}

The study sought to investigate performance of students in science subject in primary school in relation to the performance of physics in high school. Through documents analysis (KCPE Certificate and End of term physics exam), out of the 270 students who participated in the study, $88.8 \%$ scored an average mark of above $50 \%$, while $77 \%$ of the same students had scored an average mark of above $50 \%$ in the End of Term physics Examination. $11.1 \%$ scored a mark below average in KCPE examination, while $22.2 \%$ of the same students scored a mark below average in the school internal examination done previously before the research.

According to the data, students averagely performed well in science at KCPE, however performance in high school is skewed to the negative. These results from teaching of science subjects in high school as individual subjects: Chemistry, Physics and Biology. The study also confirmed that students cannot figure out the relationship between science in primary school and secondary school. This was mentioned by one of the student when asked about the relationship between science learnt in primary school and science learnt in the secondary school.

\section{Implications to Vision 2030}

Kenya's vision 2030 initiative aims at making the country a newly industrializing middle income country providing high quality life for all its citizens. In tandem with this overall vision, the vision for the education sector for 2030 is "to have globally competitive quality education, training and research for sustainable development." It has further been emphasized that to achieve this vision, a number of strategic areas, namely, access, quality, equity, science, technology and innovation have been identified for support based on their impacts on the economic, social and political pillars. Physics subject is expected to play an important role in the achievement of Vision 2030 because it can steer industrialization and innovation and thus accelerate economic growth that will in turn improve the quality of lives.

The findings of this study reveal that enrolment of students to physics subjects is low. More worrying also is that performance in physics subject remains just average in schools that are deemed to be top performing. The boys' schools maintained a lead in physics but the results show that this performance is anything but average especially. The implication is that the majority of students are under-performing making access to physics oriented 
courses which can spur industrialization difficult. Implementing Vision 2030 will require more knowledge based skills in technical subjects in which physics is prerequisite. This calls for more training in technological related courses. If secondary school graduates are not enrolling in physics and realizing the required grades in order to enroll in such courses, the vision remains just a mirage. There must therefore be concerted effort among all stakeholders to address the problem of low enrolment of students to physics subjects. Policy strategies for science and technology in education point to the establishing and equipping of science laboratories in all secondary schools to encourage schools to give prominence to science subjects. This study reveals that such a policy has been more theoretical than practical as a number of schools identified, lack of sufficient facilities as a factor contributing to poor performance in physics. To put vision 2030 on course, the issues of provision of science facilities in schools ought to be revisited particularly in recently established schools which rely on Subsidized Secondary Education Funds to meet the educational needs of students from low socio-economic status. Such students need the quality life articulated in vision 2030 which can be brought about through industrialization and innovation.

\section{CONCLUSION}

The main findings of the study is that there are factors which influence enrolment and performance in physics among students in secondary schools, but very little has been done on the management of these factors to bring about high enrolment and performance of the subject. The influence is highly felt on the attitude of students towards physics as a subject. Students have a formed opinion on the nature of the subject, majorly on difficulty level and having mathematical elements which scares them off. The study revealed that, much of the encouragement and change of mind towards the subject has been done by teachers. Teachers do these through open forums, talent days and lectures on career selection and job markets available nationally and globally.

Teachers find most of the topics in physics easy to handle, however, some topics like electromagnetic induction, reflection, electronics and waves tend to be challenging. The mathematical part in physics impact on girl's performance in physics, the learners should be encouraged to practice mathematics more often and mathematics teachers should be involved in teaching of mathematics concepts in physics.

Document analysis (KCPE results) revealed that learner's background in science at primary level was a bit weak as grades were averagely of a C plain, which indicates that most students have weak background in sciences from primary school. Physics is highly regarded subject in the Kenyan science curriculum but its performance and enrolment of students has not been impressive and thus jeopardize Kenyan vision 2030.

\section{RECOMMENDATIONS}

Based on the findings of this study the following recommendations are made.

i) Curriculum developers should link primary school science syllabus and secondary school sciences in order to provide a smooth transition between the two levels of education.

ii) Teachers teaching physics should constantly consult and work closely with mathematics teachers. This will help in identifying and solving problems that arise as a result of the overlap of content between the two subjects. Guidance should also be provided to the students on the significance of mathematics as an instrument of communication. This will lead to appreciation of mathematical calculations in physics and thus raise the students' attitude towards physics.

iii) Future studies should focus on finding the reasons why the mentioned topics are considered difficult in order to address them amicably. The perception of the subject among students should also receive attention, as most students tend to opt for other science subjects (Biology and Chemistry). Delivering of physics topics well and using practical and experiments can improve perception and understanding of the subject by the students.

iv) Importance's and applications of physics in particularly to attainment of Kenyan vision 2030 should be emphasized in levels of education.

\section{REFERENCES}

Adeoye AF (2010). Impact of Systematic Assessment in Instruction on Secondary Students Physics Achievement at Cognitive level of Knowledge. Eurasia J, Physics and Chem. Educ. 2(1): 44-52

Boyes E, Dickson D (2003). Why Aren't Secondary Students Interested in Physics? Physics Education, 38(4): 324-329.

Government of Kenya (2007). New Sessional Paper No. 3 on Pupulation for National Develop.

Kariuki NM (2007). Determinants of Enrolment and performance in Physics among Secondary Students of Maragua District, Kenya. Unpublished Med Thesis, Kenyatta

Keith M (1996). Introduction to high school physics 2nd edition Oxford Uni. Press

KNEC (2008). Year 2006-2007 KCSE examination and performance report. Nairobi

KNEC (2012). Year 2010-2011KCSE examination and performance report. Nairobi

KNEC (2014). Year 2012-2013 KCSE examination and performance report. Nairobi

Kombo DK, Tromp DA (2006). Proposal and Thesis Writing. Nairobi: Paulines Publications Africa

Lyons T (2005). The puzzle of falling enrolment in physics and chemistry courses; putting some pieces together. National Centre of Science, ICT, and Mathematics Education for Rural and Regional Australian Uni. 
094 Educ. Res.

Ministry of Education, Science and Technology. (2007). Report of the Education Sector Review. Nairobi. MOEST.

Mwangi DT (1983). Factors influencing the performance and learning of mathematics among secondary school students in Kenya . Nairobi: Kenyatta University College, Bureau of Education Research.

Nathan S, Brian L (1995). Physics laboratory Manual: A students' physics practical guide. European J. sci. edu. 5 203-15

Nderitu MK (2007). Determinants of enrolment and performance in physics in selected sec. sch. in Murang'a District. Unpublished Med Thesis

Osborne J, Simon S, Collins S (2003). Attitude towards sciences: Review of the literature and its implications. Intl. J. sci. edu.
Otieno AO (2009). Drug Abuse in Kisumu Town Western Kenya. Ajfand Online, Volume 9 No. 3, Page 846-858.

Semela T (2009). Who is joining Physics and why? Factors influencing the choice of physics among Ethiopian Uni. students. J. Environ. and Sci. Edu. Vol.5 No 3 July $2010319-340$

UNESCO (2003). Gender and Education for All. The leap to Equality. EFA Global Monitoring Report 2003/4. Paris: UNESCO. Uni.

Waititu MM (2004). Exploring Syllabus. Unpublished Med Theses. 